\title{
O outro lado da formalização do trabalho do care no Brasil ${ }^{1}$
}

\begin{abstract}
Resumo
Com base na consideração de abordagens latino-americanas sobre a informalidade desde os anos 1960 e no estudo de três casos de trabalho do care, este artigo questiona a tendência atual de formalização do Estado brasileiro em uma perspectiva relacional. O modo pelo qual o Estado regula o trabalho contribui não somente para a despolitização do governo dos pobres, mas mais amplamente para a governança neoliberal. $O$ artigo mostra como esta, além da instrumentalização do trabalho das mulheres pobres, os individualiza e cria novas hierarquias. A novidade dessas políticas reside na ativação e na responsabilização dos indivíduos pelo fracasso programado dos seus esforços permanentes de empreendedorismo de si, que se situa nos antípodas do direito.
\end{abstract}

Palavras-chave: América Latina; Neoliberalismo; Políticas sociais; Formal/informal; Trabalho do cuidado

\section{Isabel Pauline Hildegard Georges}

Doutora em Sociologia pela

Université de Paris VIII - St. Denis, França. Pesquisadora do Institut de Recherche pour le

Développement - IRD/UMR

Développement et sociétés

(IRD/Paris I-IEDES), França.

Professora credenciada do

Programa de Pós-Graduação em

Sociologia do Departamento de

Sociologia da Universidade

federal de São Carlos - UFSCar e

Pesquisadora colaboradora da

Universidade de São

Paulo/Centro de Estudos dos

Direitos da Cidadania.

França

isabel.georges@ird.fr

\section{Tradução}

Fernando Coelho

Mestre em Estudos da Tradução pela Universidade Federal de

Santa Catarina-UFSC com

Graduação em Filosofia, Letras-

Italiano e Letras - Francês pela

UFSC. Doutorando em Linguística

na UFSC.

Brasil

zeffiretto@gmail.com

\footnotetext{
${ }^{1}$ Artigo publicado em francês na Itália, na revista "Studi di Sociologia", Milano/Itália, n. 3, p. 299-312, 2015.
} 


\section{The other side of formalization of care work in Brazil}

\begin{abstract}
In the context of Latin-American studies of informality since the 1960 , this article proposes a reflexion about the actual (paradoxical) tendency of formalization of the Brazilian State in a relational perspective, with regard to three cases of care work. The depolitization of the government of the poor (women) is based on the nature of the formalization of care work. More generally, this article show how these neoliberal forms of government imply the functionalization of the work of women, and lead, more largely, to new hierarchies in between them. On the antipodes of the notion of right, these neoliberal politics are based on the activation and responsibilization of individuals for the result of their permanent self-entrepreneurship, potentially vowed to loose.
\end{abstract}

Keywords:: Latin America; Neoliberalism; Social politics; Formal/informal; Care work.

\section{Les revers de la formalisation dans le travail du care au Brésil}

\begin{abstract}
Résumé
À partir d'une mise en perspective des approches latino-américaines de l'informalité depuis les années 1960 et l'étude de trois cas de figure du travail du care, cette communication interroge la tendance actuelle de formalisation de l'État brésilien dans une perspective relationnelle. La manière dont l'État réglemente ce travail contribue très directement non seulement à la dépolitisation du gouvernement des pauvres, mais plus largement, à la gouvernance néolibérale. L'article montre comment celle-ci, au-delà de l'instrumentalisation du travail des femmes pauvres, les individualise et crée de nouvelles hiérarchies. La nouveauté de ces politiques réside dans l'activation et la responsabilisation des individus pour l'échec-préprogrammé de leurs efforts permanents d'entreprenariat de soi, qui se situe aux antipodes du droit.
\end{abstract}

Mots-clés: Amérique Latine; Néo-libéralisme; Politiques sociales; Formel//nformel; Travail du care.

\section{Para citar este artículo:}

GEORGES, Isabel Pauline Hildegard. O outro lado da formalização do trabalho do care no Brasil. Revista PerCursos. Florianópolis, v. 16, n. 32, p. 169 - 187, set./dez. 2015. Título original Les revers de la formalisation dans le travail du care au Brésil, publicado na Revista Studi di Sociologia, Milano/Itália, n. 3, p. 299-312, 2015.

DOI: $10.5965 / 1984724616322015169$

http://dx.doi.org/10.5965/1984724616322015169 


\section{Introdução}

$\mathrm{Na}$ tradição dos trabalhos sobre os países "do sul”, que há muito tempo questionam uma perspectiva dual do mercado de trabalho (a partir das polarizações entre moderno e arcaico, formal e informal, legal e ilegal, etc.) (LAUTIER, 1994; Lautier, PEREIRA, 2004; MORICE, 2010; TARRIUS, 2014), propomos uma reflexão sobre as transformações do lugar da informalidade e sobre as modalidades da ação pública, cruzando-a com uma abordagem em termos de gênero. Com efeito, para retomar a questão colocada por Bruno Lautier, que inspirou mais de um autor (FONTAINE, WEBER, 2012): “Quem lucra com as regras?”, sugerimos uma atualização e uma ampliação dessa problemática a partir do caso brasileiro.

Nessa perspectiva, em que as contribuições da literatura latino-americana podem ajudar-nos a superar as abordagens dicotômicas (QUIJANO, 1966; SANTOS, 1979; OLIVEIRA, 1972, entre outros)? E como elas lançam luz sobre os processos de precarização em andamento em nossas próprias sociedades?

Se, dos dois lados do Atlântico, pesquisadores têm questionado há muito tempo abordagens dicotômicas dos mercados de trabalho para situar no centro do debate a questão política do interesse de tal atitude, a crítica marxista de Francisco de Oliveira (1972) das análises latino-americanas da dita "marginalidade social” (QUIJANO, 1966), ou da "massa marginal" (NUN, 1969), cuja perspectiva evolucionista tinha sido reforçada pelos estudos cepalinos (CEPAL - Comissão Econômica para a América Latina e Caribe) no início dos anos 1970 (SÁ JR., 1970; FURTADO, 1971), foi fundamental para superar a “concepção dualista que opunha um setor 'atrasado' e um setor 'moderno”" (COSTHEK , 2011). Na abordagem relacional da "Crítica da razão dualista" (OLIVEIRA, 1972, op. cit.), a manutenção das relações de produção agrárias (tradicionais) nas regiões rurais e a criação de um enorme exército industrial de reserva na cidade a fim de preservar um custo pouco elevado da mão de obra constituiriam o modo específico da acumulação capitalista "à brasileira". No contexto atual da globalização, um conjunto de análises da "velha" e da "nova" informalidade (CACCIAMALI, 2000; DEDECCA, Baltar, 1997; LIMA, 2002; SILVA, 2002; PÉREZ-SÁINZ, 1995) permitiram mostrar o surgimento de uma 
ideologia do empreendedorismo de si mesmo (DONZELOT, 1984; SILVA, 2002) como se as políticas neoliberais implementadas desde os anos 1980 tivessem levado a uma homogeneização do quadro de referências, aplicando-se inclusive às modalidades de acesso às políticas sociais pela "ativação" dos indivíduos. Se a maior parte desses estudos insistem no papel do Estado como sendo um dos atores centrais da organização das relações sociais, a interrogação da dimensão do gênero dessas políticas está longe de ser a regra.

A partir do estudo de três casos relativos à figura do trabalho do care (emprego doméstico, as "empreendedoras de moral" e diferentes categorias de agentes de execução do Estado) 2 , longe de concluir em uma ausência ou uma retirada do Estado, nossa hipótese é que sua ação é central para compreender a indefinição das fronteiras dos territórios do trabalho, do emprego, da assistência, do formal e do informal, do legal, do ilegal, etc. O objetivo final deste artigo é interrogar o sentido político desses processos de formalização/informalização simultâneos, para além de uma abordagem normativa.

\section{Três figuras de modalidades de ação pública do contexto Brasileiro: o trabalho do care (emprego doméstico, empreendedores de moral, agentes de execução do Estado)}

Para tentar compreender um pouco melhor o nosso objetivo, pareceu-nos útil deslocar um pouco o olhar para iluminá-lo sob uma nova luz, interessando-nos por um setor de atividade e um tipo de trabalho em particular, o do care ${ }^{3}$. De um modo geral, os estudos sobre o trabalho do care se interessaram sobretudo pelas mobilidades dos países “do sul” em direção ao norte (BORGEAUD-GARCIANDÍA, GEORGES, 2014), enquanto no

\footnotetext{
${ }^{2}$ As pesquisas de campo sobre as quais se apoia a análise foram realizadas no contexto de várias estadas no Brasil, da cátedra Lévi-Strauss, em diferentes universidades (Unicamp, USP-IAU, Universidade Federal de São Carlos) e de vários projetos de cooperação internacional ("As novas configurações do trabalho e trajetórias de inserção de populações de baixa renda", CNPq-IRD, 2007-2011; "A nova gestão da questão social no Brasil: entre participação e mercantilização", CNPq-IRD, 2012-2015; "Offre institutionnelle et logiques d'acteurs : femmes assistées dans six métropoles d'Amérique latine", LATINASSIST - ANR Les Suds II, 2011-2014).

${ }^{3}$ Nous définissons ici le travail du care dans une conception large, comprenant un ensemble d'activités hétérogènes qui contribuent, la plupart du temps, à accomplir la fonction de reproduction sociale dans un sens large, au-delà du soin physique porté directement aux personnes. Pour une discussion de la notion, cf. (Molinier, Paperman, Laugier, 2009 ; Gilligan, 1982 ; Tronto, 1993, entre autres).
} 
Brasil, até muito recentemente, trata-se justamente de um dos setores de atividades alimentados essencialmente pelo viés das migrações inter-regionais no interior do país.

Com efeito, diferentemente de outros países do continente latino-americano, no Brasil, o trabalho do care, e primeiramente o emprego doméstico, constitui uma situação de laboratório para observar as relações de classe entre mulheres. Ademais, o emprego doméstico, e mais amplamente o trabalho de reprodução, se situa no cruzamento da esfera privada com a pública. Nesse sentido, esse trabalho não remunerado participa do processo de reprodução das classes populares, do mesmo modo que a produção da moradia (OLIVEIRA, 1972, op. cit.), por exemplo ${ }^{4}$. A realização dessas atividades por mulheres saídas dos meios populares no domicílio de outras mulheres mais bem de vida se beneficiou, contudo, de uma tendência à formalização - permitindo o seu acesso ao emprego (registrado), e a realização de carreiras profissionais para as segundas.

De um modo geral, se este período foi marcado por um aumento das taxas de formalização do mercado de trabalho, cuja parcela na população ativa ultrapassa os 50\% e um aumento de renda média ${ }^{5}$ (LEITE, 2011), as mulheres contribuem de um modo específico para esse cenário. A extensão do assalariamento do emprego feminino é crescente, mas desigual, observando-se assim a dita "bipolarização" ou a "dualização" da atividade feminina (ARAÚJO, 2012; LOMBARDI, 2012; KERGOAT, HIRATA, 2008). O emprego feminino é estratificado e se divide, grosso modo, entre dois polos, o das profissões liberais, em que o lugar das mulheres está em expansão, de um lado, mas observa-se sobretudo uma grande concentração no outro extremo da escala das qualificações e em termos de condições de trabalho, do qual emprego doméstico constitui uma forma emblemática (LOMBARDI, 2012, op. cit.,). Angela Araújo chega a uma constatação similar interrogando a divisão social e sexual do trabalho pelo prisma da "nova informalidade", demonstrando a sub-representação das mulheres nos empregos

\footnotetext{
${ }^{4}$ Dimensão em que a participação das mulheres sempre foi notável (Bergamin, 2011), ao ponto de se tratar de uma das primeiras políticas sociais que tiveram as mulheres como beneficiárias principais (Levy et al., 2013). Aliás, a questão da inviabilização do trabalho doméstico e sua contribuição para o PIB foi objeto de uma antiga discussão nos meios feministas (Melo, 2009).

${ }^{5}$ Sobretudo em razão do aumento contínuo do salário mínimo, desde a chegada ao poder do PT em 2003.
} 
mais precários, sobretudo no interior das cadeias de terceirização, nacionais ou internacionais (ARAÚJO, 2012, p. 135 op. cit.).

Os três casos das atividades do care (emprego doméstico, "empreendedores de moral" e diferentes categorias de agentes de execução do Estado) que estudamos contribuem cada um de um modo específico para essa configuração, permitindo esclarecer um pouco melhor a maneira pela qual o Estado contribui, por meio da institucionalização dessas atividades, a disseminar essa "nova cultura do trabalho" fundada na empregabilidade do empreendedorismo de si mesmo, inclusive reconhecendo e formalizando certo número de direitos. De uma maneira ou de outra, essas três atividades contribuem para a definição concreta de uma política social e a maneira pela qual o estado toma forma junto dos indivíduos e até a maneira pela qual este último (re)produz a divisão social e sexual do trabalho (GEORGES, 2014). Com efeito, nossa questão versa sobre a judicialização das relações sociais, sobre o lugar do direito e em particular sobre os usos do direito, inclusive pelo Estado. Pois, se, parafraseando Lautier, "Somente um sistema de normas exterior à moral, o direito, pode desempenhar esse papel federador [de fundar a legitimidade de uma moral em relação a uma outra]" (LAUTIER, 2013 [2009], p. 181), dialogando com o argumento weberiano segundo o qual a moral é insuficiente por si só para conferir legitimidade, parece-nos contudo que os usos do direito pelo Estado constituem antes uma dimensão, entre outras, que confere legitimidade, mas que não a funda tampouco. Ou, para dizer de outro modo, o direito, posto a serviço do governo, pode ser pensado como o elemento de um dispositivo, como um modo de reconhecer, e neste sentido de incluir, mas também e sempre simultaneamente como uma maneira de excluir e de segmentar. O direito estaria assim sempre também na origem dos modos de contorná-lo, mobilizando diversos registros (clientelistas, paternalistas, familialistas, etc.) 


\subsection{O emprego doméstico}

O emprego doméstico no Brasil, ao contrário de outros países da América Latina ${ }^{6}$, nos quais a parcela das mulheres que trabalham no emprego doméstico é muito elevado ${ }^{7}$, se caracteriza por uma taxa de formalização do emprego comparativamente mais elevada (perto de $25 \%)^{8}$, o que é tanto mais significativo quanto cerca de $20 \%$ da população ativa feminina trabalha no emprego doméstico. Este representa um total de 6,6 milhões de pessoas, dos quais 6,1 milhões de mulheres (DIEESE, 2013, p. 3). Em termos concretos, para uma mulher de meio popular no Brasil, a passagem desse emprego em determinado momento da sua vida é quase obrigatório (VIDAL, 2007). Nessa atividade, a diversificação das situações de trabalho, e a individualização extrema da relação com o empregador na origem da desunificação da categoria, levou paradoxalmente a uma forma de negociação coletiva muito centralizada e altamente formalizada (GEORGES, 2009). Ademais, se a nova Constituição de 1988 já tinha reconhecido uma legislação específica a essa categoria, e aberto a via à "juridicização" e à “judicialização” da relação de emprego (VIDAL, 2007, op. cit.), a adoção de um conjunto de leis intensificou essa tendência, com a possibilidade de deduções fiscais para o emprego e finalmente a adoção do projeto de mudança da Constituição adotado em abril de 2013, igualando assim o emprego doméstico aos outros trabalhadores registrados (DIEESE, 2003). Ora, se o conjunto dessas mudanças reflete sem dúvida uma transformação da posição do emprego doméstico no mercado de trabalho, do seu valor relativo aos olhos das mulheres e do quadro de referências que pode entrar em jogo nas relações de

\footnotetext{
${ }^{6} \mathrm{Na}$ Argentina, por exemplo, em que a referência à figura do emprego assalariado é, contudo, muito presente, em 2003 , $96 \%$ das mulheres que trabalhavam no setor não eram declaradas aos organismos da previdência social. Se o programa de "formalização" implementado durante a última década pelo governo desencadeou uma dinâmica nesse sentido, cujos efeitos são, contudo, "profundamente ambíguos", sobretudo "em razão das características da legislação" (Tizziani, 2011).

${ }^{7}$ No conjunto dos países latino-americanos (15 selecionados), o emprego doméstico representa $15,3 \%$ do conjunto da população ativa feminina, equivalendo a $37 \%$ do emprego doméstico em nível mundial, segundo os dados da OIT (Abramo, Valenzuela, 2013).

${ }^{8}$ Segundo dados da PNAD (Pesquisa Nacional de Amostra por Domicílio)/IBGE (Instituto Brasileiro de Geografia e de Estatística), a parcela das trabalhadoras domésticas sem contrato de trabalho diminuiu consideravelmente entre 2004 e 2011 (de 57\% a 44,9\% em 2011); a parcela das trabalhadoras domésticas declaradas passou de $21,6 \%$ para $24,5 \%$ no mesmo período, uma vez que uma parte das trabalhadoras domésticas começou a trabalhar como diarista, para diferentes empregadores, cuja parcela total no emprego doméstico representa 30\% (DIEESE, 2013, p. 11).
} 
negociação entre as trabalhadoras e seus empregadores (a maior parte do tempo igualmente mulheres) - e na relação de classe entre mulheres que está em jogo aí - o surgimento simultâneo de uma mão de obra estrangeira, sobretudo latino-americana, no mercado de trabalho do emprego doméstico não é tampouco inofensivo ${ }^{9}$. Por outro lado, além das formas de autonomização que o assalariamento pode levar a essas mulheres, essas medidas fixam as mulheres, paradoxalmente, em uma posição que deriva da função social que elas assumem em seu próprio espaço privado (GEORGES, 2008).

Para além das melhoras das condições de trabalho e de emprego, entre as quais a última em data, a saber, o projeto de mudança da constituição de 2013 que prevê a abertura dos mesmos direitos para as empregadas domésticas que os outros trabalhadores têm, que podem representar, sem dúvida, essas mudanças para uma parte das mulheres brasileiras, as implicações são diversas e ambíguas. Como mostrou a mutação de uma parte das antigas trabalhadoras domésticas para um emprego de faxineira diarista, tanto por iniciativa do empregador particular, que não pode desembolsar as despesas de uma trabalhadora doméstica por mês (BRANDT, 2003), quanto das trabalhadoras domésticas, entre as quais uma parte parece igualmente preferir obter um emprego com um salário por hora mais elevado (o caso das diaristas), e mais flexível (que permite o acúmulo com outras atividades profissionais ou familiares, e com a recepção de benefícios sociais). Por outro lado, uma parte pode ainda preferir não levar a marca deste emprego na sua trajetória posterior (que seria atestado pelo registro na sua carteira de trabalho). Por outro lado, a formalização desse emprego cria igualmente um nicho mais importante para uma mão de obra de proveniência de outros países. Mobilizando o argumento de Morice \& Potot (2010), desenvolvido a partir do estudo das políticas migratórias europeias, a necessidade de obter uma licença de trabalho para entrar nesse mercado de emprego equivale ao mesmo tempo à criação de um contingente de mão de obra que não poderá preencher essas condições, e seria portanto pelo menos temporariamente obrigadas a aceitar trabalhar em condições menos favoráveis. Nesse sentido, os incentivos à formalização do emprego doméstico

\footnotetext{
${ }^{9}$ De acordo com um artigo de imprensa, o número de paraguaias passou de 68.052 em 2008, a 348.704 e 2010. (“Paraguai exporta babás para São Paulo”, Estadão, 27/03/2011).
} 
visam ao mesmo tempo à criação de um novo contingente de trabalhadoras "mais dóceis", e menos caras que a mão de obra nacional. Por último, esta política corresponde a uma maneira de o Estado brasileiro contribuir para a manutenção do status quo da divisão social e sexual do trabalho, a saber, de reatribuir às mulheres o encargo da reprodução, seja como empregadoras, seja como trabalhadoras, e portanto a uma injunção na vida privada das famílias. Estamos, portanto, muito longe de uma problemática de redistribuição dos papéis sociais para cima, ou de uma responsabilização, pelo menos parcial, da função de reprodução pelo Estado.

\subsection{As "empreendedoras de moral” e os agentes de execução do Estado: formas de instrumentalização "incrustadas"}

No que diz respeito às "empreendedoras de moral", ou seja, as gestoras de entidades de terceirização de serviços sociais, que fizeram carreira profissional em um setor do serviço social, e os agentes de execução do Estado, elas são as primeiras "beneficiárias" das políticas de terceirização no setor da assistência, como o da saúde, que foram implementadas durante a última década em São Paulo, metrópole mais dinâmica do país (GEORGES, 2014). Com efeito, a generalização da terceirização como modo de operacionalização das políticas públicas levou, nesses setores, a uma diversificação dos status, mas também a uma ampliação da oferta de empregos, permitindo tanto a realização de carreiras horizontais, entre atividades diferentes, mas situadas no mesmo nível hierárquico, quanto de carreiras profissionais ascendentes, a exemplo das carreiras invisíveis das "empreendedoras de moral” americanas estudadas por Arlène Kaplan Daniels (1988). Ora, se no grupo estudado por Kaplan Daniels tratavase de mulheres originárias das classes superiores americanas, as gestoras que estudamos são de origem popular, como os agentes de execução que trabalham nessas entidades, geralmente de matrizes religiosas, como as de uma das ONGs em que fizemos nossa pesquisa de campo (cf. o quadro abaixo). 


\section{Uma empresa de moral}

A Comunidade da Felicidade - a ONG de origem religiosa que terceiriza o PAF em que fizemos nossa pesquisa em 2011 - é ligada a uma igreja evangélica neopentecostal ${ }^{10}$, fundada em 1979. O trabalho voluntário começa em 1982, a igreja oferece cuidados médicos aos membros da comunidade, em uma sala adjacente. A profissionalização do trabalho inicia com a criação da ONG Fundação da Comunidade da Felicidade em 1996 e se desenvolve sobretudo nos anos 2000, com a entrada na política do filho do fundador. Em 2007, a ONG aceita pela primeira vez fornecer um serviço para a prefeitura (uma creche para a qual ela faz um balanço), experiência que lhe assegura a obtenção de outros contratos. Se em 2008 a ONG emprega 70 trabalhadores em tempo integral (CLT), em 2010 eles já são 270, mais 180 trabalhadores voluntários (que contribuem com um ou dois dias de trabalho semanais). Os gestores (13 pessoas) pertencem quase todos à igreja, assim como os seus cônjuges, para $1 / 3$ dos trabalhadores. A ONG realiza atualmente 8 serviços de assistência para a prefeitura: 4 creches, 2 Programas de Ação Família, uma sopa popular e um abrigo destinado a mulheres vítimas de violência doméstica. A sede da ONG se situa em um grande imóvel de 4 andares no centro de um bairro de periferia, abriga uma policlínica, uma farmácia (distribuição de medicamentos doados) e realiza a distribuição de leite e de cestas básicas.

Inspirando-nos na análise de Howard Becker (1963) sobre o trabalho dos empreendedores de moral (moral cruzaders) assim como sobre o daqueles que aplicam as regras (rule enforcers), adaptando ao caso do trabalho feminino realizado em entidades assistenciais, trata-se de uma forma de instrumentalização do trabalho das mulheres pelo Estado, jogando com suas pretensas possibilidades de mobilidade social. Nesta perspectiva, a integração de antigos beneficiários da ajuda social, como o agente de execução, constitui o início dessa carreira "moral” cujo trabalho de gestor constitui o fim. Para resumir, o Estado joga com a condição dessas mulheres pobres, com um número de

\footnotetext{
${ }^{10}$ Mas que não preconiza a teologia da posteridade. A igreja defende, contudo, valores da família, e veicula uma imagem paterna, e até paternalista do fundador nos diferentes fascículos publicados.
} 
alternativas reduzidas, para colocá-las no trabalho, a fim de que elas coloquem ao trabalho outras mulheres, em forma de escada.

Os agentes de execução do Estado (agentes comunitários de saúde (ACS), agentes de proteção social (APS), atuais "orientadores"

Os ACS foram integrados no Sistema Único de Saúde (SUS) - inserido na nova constituição de 1988 - em 1991, e no Programa Saúde Família (PSF) em 1994, que se tornou a Estratégia Saúde Família atualmente. Em 2008, 221588 ACS trabalham em 28452 equipes multidisciplinares do PSF e estão encarregados de uma população de 103 milhões de brasileiros. O PSF é realizado por intermédio de uma equipe multidisciplinar. Cada equipe, que trabalha em uma unidade de saúde, é responsável por cerca de 5000 pessoas, cada agente por cerca de 1000 pessoas (em torno de 200 domicílios). Os agentes, tendo no mais das vezes o ensino médio, devem morar no mesmo bairro que os usuários da unidade. Eles ganham cerca de 1,5 salários mínimos, e dispõem de um contrato de trabalho estável com um dos três organismos (OS) que terceirizam os serviços de saúde básica no município de São Paulo. Os seus horários de trabalho são relativamente flexíveis, em função das necessidades, em uma base de 8 horas diárias. Esses agentes "de ligação" entre a unidade e a população estão encarregados de um serviço de prevenção de saúde, por intermédio de visitas domiciliares (algumas categorias são prioritárias). O seu trabalho passa por um controle de produtividade permanente e informatizado por meio de relatórios. Em 2006, o Programa Ação Família (PAF) se encarrega de 30000 famílias que vive em situação de "vulnerabilidade social", com o objetivo de atingir a totalidade das famílias recenseadas nessa situação (337000 famílias na cidade de São Paulo, ou seja, 1,4 milhões de pessoas). Em cada ONG ou associação encarregada do Programa, uma modalidade local do serviço de assistência previsto pela Constituição, trabalha uma equipe multidisciplinar recrutada por esta. Os agentes dispõem de um contrato de trabalho pela duração do contrato de terceirização com a prefeitura para a realização do programa; o seu nível salarial é ligeiramente superior ao dos ACS. Contrariamente a esses últimos, que são quase exclusivamente mulheres, os APS são às vezes moços. Eles têm igualmente nível de estudos médio. A proximidade do domicílio do lugar de trabalho constitui uma vantagem, mas não é 
obrigatória. O seu papel consiste em organizar reuniões sócio-educativas com os usuários de que o programa se encarrega, em realizar visitas domiciliares, em implementar ateliês "profissionalizantes" (costura, pedicure, cabeleireiro, confeitaria, etc.,) e mais geralmente em ajudar as famílias nos seus procedimentos administrativos para ter acesso aos serviços e auxílios do Estado. Mas recentemente, os serviços de assistência municipal apelam aos serviços dessas entidades para realizar o controle das condicionalidades para a atribuição do auxílio social, como o Bolsa Família, em particular depois da redefinição do serviço em 2011 em um objetivo de homogeneizar o serviço.

Ao passo que a criação da categoria dos agentes comunitários de saúde, que foram integrados no Sistema Único de Saúde em 1991, e no Programa Saúde Família em 1994, assim como o seu reconhecimento em nível nacional em 2002 é oriundo de experiências de voluntários e militantes locais diversas e responde, portanto, a uma reivindicação da população (Lima \& Cockell, 2008/2009), essa experiência “virtuosa", que serviu de modelo para outras políticas sociais, como as de assistência, não escapou às políticas neoliberais dos anos 1990, de redução de custos, que se exprimiu pela descentralização administrativa e uma espécie de "reforma interna" do Estado. Desta forma, se a terceirização sistemática aumentou a cadeia de produção dos serviços públicos, e aumentou assim o volume dos empregos, estes se caracterizam, entretanto, pelo baixo nível dos salários e pela instabilidade no tempo (em razão dos contratos de terceirização). Assim, em troca de um número de vantagens limitado (uma carreira profissional relativa para os gestores, o acesso a um emprego com registro em carteira em territórios em que o emprego é raro) - mas não por isso desinteressante para as mulheres - elas aceitam, cada uma em seu nível, fazer a triagem entre outras mulheres, colocá-las em concorrência, para decidir se elas têm ou não direito a uma cidadania pelo trabalho (no caso do seu recrutamento por uma das associações/ONGs, por exemplo), ou a uma "cidadania pela assistência" - se é que isto existe. Nesse sentido, elas realizam um 
trabalho de pacificação, evitando o conflito, ou seja, uma forma de "trabalho sujo" (HUGHES, 1951) 11 .

Nos três casos, o Estado intervém na repartição entre as atividades consideradas como pertencendo à esfera pública ou privada, publicizando um certo número entre elas, que tinham sido consideradas como pertencendo à esfera privada, indo até o seu controle no interior do espaço doméstico, na ocasião das visitas domiciliares dos beneficiários do auxílio social realizadas pelas diferentes categorias de agentes. Nesse sentido, a "formalização" dessas atividades - realizadas antes no contexto do voluntariado, da militância - coloca também as relações domésticas na praça pública (da educação das crianças até os conflitos conjugais), e portanto mesmo o "direito à assistência" se vê sujeito ao "empreendedorismo de si mesmo", em função da capacidade individual de "transformação social", um dos critérios de avaliação das trajetórias das famílias cujas mulheres são beneficiárias do auxílio social, sendo “avaliadas" pelas entidades de assistência do "terceiro setor" estudados.

\section{Conclusão: que ampliações são possíveis?}

No sentido de uma abordagem sistemática, do dispositivo de governo foucaultiano (1994), a maneira pela qual o Estado regulamenta essas diversas atividades do care contribui muito diretamente não somente para a despolitização do governo dos pobres (LAUTIER, 2013 [2009]), mas mais amplamente, segundo nossa hipótese de trabalho, ao governo neoliberal. Este se caracterizaria, ademais, por uma superpresença do Estado que interviria tanto como poderoso intermediário para facilitar a presença e as vantagens (econômicas, de poder) da iniciativa privada, como enquanto iniciador de um dispositivo de gestão das pessoas individualizadas e colocadas em concorrência umas com as outras. O lugar das mulheres se situaria justamente no interior desse dispositivo, na ação de pôr ao trabalho mulheres por outras mulheres, de diferentes graus de pobreza. Este fato de pôr em concorrência os indivíduos passaria, por um lado, pela

\footnotetext{
${ }^{11}$ Para uma análise mais sistemática das ambiguidades da formalização de empregos de serviço, cf. Georges \& Vidal, 2012.
} 
atribuição coercitiva de posições e de funções sociais (de produção e reprodução), mobilizando várias políticas ao mesmo tempo (de assistência e de repressão ao mesmo tempo, por exemplo), para realizar uma “triagem" entre os destinatários eventuais. Por outro lado, essas políticas incitam paradoxalmente os indivíduos à mobilidade permanente, à “transformação social” por intermédio de empreendedorismo de si mesmo no conjunto das esferas da vida (privada, pública, profissional, religiosa, criminosa). O fracasso pré-programado desse mecanismo faz, contudo, que a responsabilidade recaia sobre o indivíduo. E seria talvez nisto que residiria o que há de novo no modo de governar do Estado neoliberal, e em um modo de ativar os indivíduos, pervertendo a própria noção de direito, e de seus usos políticos, ao passo que parece ter estado no cerne do acordo de governo que estava em vigor durante os ditos "30 gloriosos", "um modo de integração, que embora nunca tenha sido completo, e passou por inúmeras variações nacionais [...] seu sucesso pode ser medido pelo fato de que apesar disto [desta incompletude], ele se tornou, como acabo de repetir, um ideal e uma referência cultural praticamente universais." (SILVA, 2002, p. 101). "É isto que parece ter constituído o milagre da sociedade salarial: atribuir um sentido unívoco e objetividade às hierarquias sociais, criando afinidades entre a inserção produtiva, possibilidades de consumo e estilo de vida, e transformando o paradoxo que consiste na relação entre liberdade e proteção em uma conquista social, mais do que de grupos particulares." (SILVA, 2002, p. 102). Tentar descrever, e compreender o que está ocupando ou já ocupou o lugar, que foi deixado livre pelo abandono desse compromisso de governo, constitui, no momento atual, um dos principais desafios da sociologia do trabalho, e da sociologia de um modo geral - pois para compreendê-lo é necessário ultrapassar os contornos do que ficou conhecido como "o mundo do trabalho".

\section{Referências}

ABRAMO, Laís, VALENZUELA, Maria Elena Genre et marché du travail en Amérique latine. In : Dans M. Maruani (Org.). Travail et genre dans le monde, l'état des savoirs. Paris : La Découverte, 2013, p. 182-193. 
ARAUJO, Angela Carneiro Informalité et rapports de genre. In : GEORGES, Isabel LEITE Marcia Paula (Orgs.), Nouvelles configurations du travail et economie sociale et solidaire. Paris: Harmattan, 2012.

BECKER, Howard S. Outsiders. New York: The Free Press of Glencoe, 1963.

BERGAMIN, Maria de Aguiar. Experiência democráticas de trabalho: dois casos em SãoPaul : Mutirão Recanto da Felicidade e Banco Comunitário União Sampaio. 2011.Thèse (Doctorat de sociologie) - Universidade fédérale de São Carlos, Doutorado em Sociologia, São Carlos, 2011.

BORGEAUD-GARCIANDIA, Natacha; GEORGES, Isabel Introduction : travailleuses en migration dans “les Suds". Déplacements de regards, reconfigurations de l'objet. Revue Tiers Monde, n. 217, p. 7-24, 2014.

BRANDT, Maria Elisa Almeida Minha area é casa de família: o emprego doméstico na cidade de São Paulo. 2003. Tese de doutorado em Sociologia - Universidade de São Paulo, Doutorado em Sociologia, São Paulo, 2003.

CACCIAMALI, Maria Cristina Globalização e processo de informalidade. Economia e sociedade, n. 14, p. 153-174, 2000.

COSTHEK, Abílio, Ludmila Les réseaux invisibles de la surexploitation du travail : inégalité sociale, informalité et accumulation capitaliste. Les Mondes du travail, n. 9-10, p. 41-52, 2011.

DANIELS, Kaplan, Arlène Invisible Careers: women civic leaders from the volunteer world. Chicago: University of Chicago Press, 1988.

DEDECCA, Cláudio Salvador; BALTAR, Paulo Eduardo Mercado de trabalho e informalidade nos anos 90. São Paulo, Estudos Econômicos, n. 27, n. especial, p. 65-84, 1997.

DIEESE O emprego doméstico no Brasil. Estudos e Pesquisas, n. 68, 2013.

DONZELOT, Jacques L'invention du social. Paris: Fayard, 1984.

FONTAINE, Laurence; WEBER Florence (Eds.) Les paradoxes de l'économie informelle: à qui profitent les règles?, La Découverte, terrains du siècle. Paris: Karthala, 2012.

FOUCAULT, Michel La Gouvernamentalité. In: FOUCAULT, M. Dits et écrits. Tome 3, Paris: Gallimard, 1994, p. 635-657. 
FURTADO, Celso Subdesenvolvimento e estagnação na América latina. Rio de Janeiro : Civilização Brazileira, 1966.

GEORGES, Isabel, «Reconfiguration des politiques sociales au Brésil. Le genre de l'assistance à São Paulo. ", Travail, Genre et Sociétés, n. 32, p. 45-61, 2014.

GEORGES, Isabel “¿Hacia una nueva división social y sexual del trabajo en Brasil? Transformaciones del papel del Estado, de las configuraciones familiares y de los empleos de servicio a las personas.", Universidad Autónoma de Nuevo León. Escritos

Sociológicos, n. 12, no prelo, 2014.

GEORGES, Isabel «L'emploi domestique : constructions institutionnelles et identitaires (Brésil, São Paulo ", Comunicação oral, Congrès de l'Association Française de Sociologie, RT 35 Sociologie de l'engagement, de la vie associative et du bénévolat, 14-17 Avril, 2009, Université de Paris VII, Site des Moulins, Paris.

GEORGES, Isabel «L'emploi domestique au croisement de l'espace public et privé. Femmes de milieu populaire à São Paulo (Brésil) », Autrepart, « Variations et dynamiques urbaines», n. 47, p. 57-71, 2008.

GEORGES, Isabel ; VIDAL, Dominique La formalisation de l'emploi à l'épreuve du travail invisible. Deux cas de figure de travailleuses de service au Brésil. Sociétés contemporaines, n. 87, p. 25-47, 2012.

HUGHES, E.S.. Studying the Nurse's work. American Journal of Nursing, n. 51, p. 294-295. may, 1951.

KERGOAT, D.; Hirata, H.Divisão sexual do trabalho profissional e doméstico Brasil, França e Japão. In: COSTA, Dans A.O.; SORJ, B., BRUSCHINI, M.-R.; HIRATA , H. (Orgs.), Mercado de trabalho e gênero, comparações internacionais. Rio de Janeiro: FGV Editora, 2008. p. 263-278.

LAUTIER, Bruno L'économie informelle dans le tiers monde. Paris : Lla Découverte, coll. «Repères». 1994.

LAUTIER, B. Gouvernement moral des pauvres et dépolitisation des politiques publiques en Amérique latine. In: BORGEAUD-GARCIANDIA, N.; LAUTIER, B.; PENAFIEL, R.; TIZZIANI, A. (Orgs.). Penser le politique en Amérique Latine: la recréation des espaces et des formes politiques. Paris: Karthala, 2009. p. 19-36.

LAUTIER, Bruno ; PEREIRA, Marques Jaime Brésil, Mexique : deux trajectoires dans la mondialisation. Paris: Karthala, 2004. 
LEITE, Márcia Paula de O trabalho no Brasil dos anos 2000: duas faces de um mesmo processo. In: OLIVERIA, Roberto Veras de; GOMES, Darcilene, TARGINO, Ivan (Orgs). Marchas e Contramarchas da informalidade do trabalho. João Pessoa: UFBP, 2011, p. 2963.

LEVY, Charmain ; LATENDRESSE, Anne ; CARLE-MARSAN, Marianne Mouvement populaire urbain et femmes au Brésil: vers une féminisation des politiques publiques de I'habitation. In : TOMAZINI, Dans C.; LUKIC, M. Rocha (Orgs.). L'analyse des politiques publiques au Brésil. Paris : Harmattan, 2013.

LIMA, Jacob Carlos; COCKELL, Fernanda Flávia As novas institucionalidades do trabalho no setor público: os agentes comunitários de saúde. Trabalho, Educação, Saúde, v. 6, n.3, p. 481-501, 2008/2009.

LIMA, Jacob Carlos; SOARES, Maria José Trabalho flexível e o novo informal. Caderno CRH, n. 37, p. 163-181, 2002.

LOMBARDI, Maria-Rosa Annotations sur les inégalités de genre du marche du travail". In GEORGES, Isabel LEITE, Márcia de Paula (Orgs.). Nouvelles configurations du travail et economie sociale et solidaire. Paris: Harmattan, 2012, p. 91-110.

MELO, Hildete Pereira de, Castilho, M. «Trabalho reprodutivo no Brasil: quem faz? ». Rev. Econ. Contemp. [online] , v.13, n.1, p. 135-158, 2009. ISSN 1415-9848. Disponivel em : <http://dx.doi.org/10.1590/S1415-98482009000100006>. Acesso em: 20 de abril de 2014.

MORICE, Alain Potot, Swanie Introduction : Travailleurs étrangers entre émancipations et servitudes. In : MORICE, A. ; POTOT, S. (Dir.). De l'ouvrier immigré au travailleur sans papiers: les étrangers dans la modernisation du salariat. Paris : Karthala, 2010, p. 5-22.

NUN, J. L. Superpopulación relativa, ejército industrial de reserva y masa marginal. Revista Latinoamericana de Sociología, v. 5, n. 2, 1969.

OIT. Organização International de Trabalho. Employment, income and inequality : a strategy for increasing productive employment in Kenya, Geneves. In : OLIVEIRA, F. de. “A economia brasileira: crítica à razão dualista”. Estudos CEBRAP, n. 2, outubro 1972.

OLIVEIRA, Francisco de. "A economia brasileira: crítica à razão dualista", Novos Estudos CEBRAP, 2, 1972, p.3-82.

PEATTIE, L. An Idea in good currency and how it grew: the Informal Sector. World Development, v. 15, n.7, p.851-860, 1987.

PÉREZ-SÁINZ, J. P. Globalización y neoinformalidad en America latina. Nueva Sociedad, n.135, p. 36-41, 1995. 
QUIJANO, A. Notas sobre el concepto de 'marginalidad social'. Santiago: División de Assuntos Sociales: Cepal, 1966. Mimeo,

SÁ JR. F. (Ed.) . Subemprego, problema estrutural. Rio de Janeiro: Vozes, 1970.

SANTOS, W. G. dos. Cidadania e justiça. Rio de Janeiro: Graal, 1979.

SASSEN, S. Essays on the new mobility of people and money. New York: The New York Press, 1998.

SILVA, A. L. Machado da. Mercados metropolitanos de trabalho manual e marginalidade: mémoire de maîtrise en sociologie. Rio de Janeiro: Museu Nacional: UFRJ, 1971.

SILVA, A. L. Machado da. Da informalidade a empregabilidade. Caderno CRH, Salvador, n. 37, p. 81-109, 2002

SILVA, A. L. Machado da. Sociabilidade violenta : por uma interpretação da criminalidade contemporânea no Brasil urbano. Sociedade e Estado. Brasília, v. 19, n.1, p. 53-84, 2004.

TARRIUS, A. Transmigrations européennes de travailleuses du sexe balkaniques et caucasiennes accompagnées de parentèles féminines. Revue Tiers Monde, n.217, jan.mar., p. 25-43, 2014.

TIZZIANI, A. Entre travail « formel » et « informel » : la législation du travail et sa mise en pratique dans le secteur de l'emploi domestique dans la ville de Buenos Aires. Les Mondes du travail, n. 9/10, p.41-52. printemps-été, 2011.

TRONTO, J. Moral boundaries: a political argument for an ethic of care. New York : Routledge, 1993.

VIDAL, D. Les bonnes de Rio : emploi domestique et société démocratique au Brésil. Villeneuve d'Ascq: Presses universitaires du Septentrion, 2007.

WACQUANT, L. Punir les pauvres :le nouveau gouvernement de l'insécurité sociale. Marseille : Agone, 2004. 
Recebida em: 15/09/2015 Aprovada em: 19/10/2015

Universidade do Estado de Santa Catarina - UDESC

Centro de Ciências Humanas e da Educação - FAED

Revista PerCursos

Volume 16 - Número 32 - Ano 2015 revistapercursos@gmail.com 